\title{
Industry 4.0 Concept: Background and Overview
}

\author{
https://doi.org/10.3991/ijim.v11i5.7072 \\ Andreja Rojko \\ ECPE European Center for Power Electronics e.V., Nuremberg, Germany \\ andreja.rojko@ecpe.org
}

\begin{abstract}
Industry 4.0 is a strategic initiative recently introduced by the German government. The goal of the initiative is transformation of industrial manufacturing through digitalization and exploitation of potentials of new technologies. An Industry 4.0 production system is thus flexible and enables individualized and customized products. The aim of this paper is to present and facilitate an understanding of Industry 4.0 concepts, its drivers, enablers, goals and limitations. Building blocks are described and smart factory concept is presented. A Reference Architecture Model RAMI4.0 and role of standardization in future implementation of Industry 4.0 concept are addressed. The current status of Industry 4.0 readiness of the German companies is presented and commented. Finally it is discussed if Industry 4.0 is really a disruptive concept or simply a natural incremental development of industrial production systems.
\end{abstract}

Keywords-Industry 4.0, Cyber-Physical Systems, Enterprise-ResourcePlanning, Manufacturing Execution System.

\section{$1 \quad$ Introduction}

Industrial production is nowadays driven by global competition and the need for fast adaptation of production to the ever-changing market requests. These requirements can be met only by radical advances in current manufacturing technology. Industry 4.0 is a promising approach based on integration of the business and manufacturing processes, as well as integration of all actors in the company's value chain (suppliers and customers). Technical aspects of these requirements are addressed by the application of the generic concepts of Cyber-Physical Systems (CPS) and industrial Internet of Things (IoT) to the industrial production systems. The Industry 4.0 'execution system' is therefore based on the connections of CPS building blocks. These blocks are embedded systems with decentralized control and advanced connectivity that are collecting and exchanging real-time information with the goal of identifying, locating, tracking, monitoring and optimizing the production processes. Furthermore, an extensive software support based on decentralized and adapted versions of Manufacturing Execution Systems (MES) and Enterprise Resource Planning (ERP) is needed for a seamless integration of manufacturing and business processes. The third important aspect is handling of a big amount of data collected from the processes, machines and products. Typically the data is stored in a cloud storage. This data 
requires extensive analytics that lead from the 'raw' data to the useful information and, finally to the concrete actions that support an adaptive and continuously selfoptimizing industrial production process.

Due to the importance of this transition for the position of a country in a global market, some government-led initiatives were introduced all-around the world to support the transition. Industry 4.0, as the first such initiative and inspiration for other initiatives, comes from Germany and will be addressed in detail in this paper. Similar concepts that were initiated in other countries are shortly presented in the continuation.

The concept of Industrial Internet has been brought up in North America by the General Electric company in late 2012. It is seen as a tight integration of physical and digital worlds that combines big data analytics with the Internet of Things. The concept assumes a much broader application area as the Industry 4.0 and covers power generation and distribution, healthcare, manufacturing, public sector, transportation and mining [1]. Within the Industrial Internet consortium that was founded by General Electrics and some other companies [1], it has been estimated that $46 \%$ of the global economy can benefit from the Industrial Internet.

In France, the concept 'Industrie du futur' was introduced as a core of the future French industrial policy. It is based on cooperation of industry and science and built on five pillars: (1) cutting edge technologies including additive manufacturing, virtual plant, IoT, and augmented reality, (2) supporting the French companies, especially small to middle ones, to adapt to new technologies, (3) extensive employees' training, (4) strengthening international cooperation around industrial standards and (5) promotion of French industry of the future [2].

Next similar initiative 'Made in China 2025' was introduced in 2015 [3]. It was initiated by the China Ministry of Industry and Information Technology in cooperation with many experts from the China Academy of Engineering. The main goal of this initiative is to comprehensively upgrade Chinese industry by drawing direct inspiration from Germany's Industry 4.0 concept and adapting it to the China needs. The transformed manufacturing should be innovation-driven. Also other elements like sustainable development and green energy are considered. Ten priority sectors were identified starting from information technology, robotics and automated machine tools. The long term goals are to reform China manufacturing industry, to move from the high number of low-cost products to high-quality products and to take over Germany and Japan dominance in manufacturing until 2035, in order to evolve into the industry world superpower until 2049.

This paper will focus on the Industry 4.0 concept introduced by the Germany government aiming at industrial production systems. Background of the concept, development plan and current state will be addressed. Some software technological background issues, which reflect essential aspects of Industry 4.0 concept, will be presented.

The paper is structured as follows. The second section presents the core idea of Industry 4.0, its origin, goals and elements as well as Industry 4.0 production system (smart factory). Also IT/software support is addressed. In the third section a Reference Architecture Model RAMI 4.0 that sets the basis the for standardization activi- 
ties is described. In the fourth section the readiness of companies for Industry 4.0 is discussed and a concrete example of a company that has already adopted most of the Industry 4.0 elements is presented. In the last section conclusions are drawn and general topics are discussed.

\section{Core idea of Industry 4.0}

\subsection{Through the industrial revolutions}

Stages in the development of industrial manufacturing systems from manual work towards Industry 4.0 concept can be presented as a path through the four industrial revolutions. The development is depicted in Figure 1.

The first industrial revolution began with the mechanization and mechanical power generation in $1800 \mathrm{~s}$. It brought the transition from manual work to the first manufacturing processes; mostly in textile industry. An improved quality of life was a main driver of the change.

The second industrial revolution was triggered by electrification that enabled industrialization and mass production. Often mentioned in this context is a quote of Henry Ford, who said about the Ford T-Model car 'You can have any colour as long as it is black.'. The quote captures well the introduction of mass production but without the possibility of products' customization.

The third industrial revolution is characterized by the digitalization with introduction of microelectronics and automation. In manufacturing this facilitates flexible production, where a variety of products is manufactured on flexible production lines with programmable machines. Such production systems however still do not have flexibility concerning production quantity.

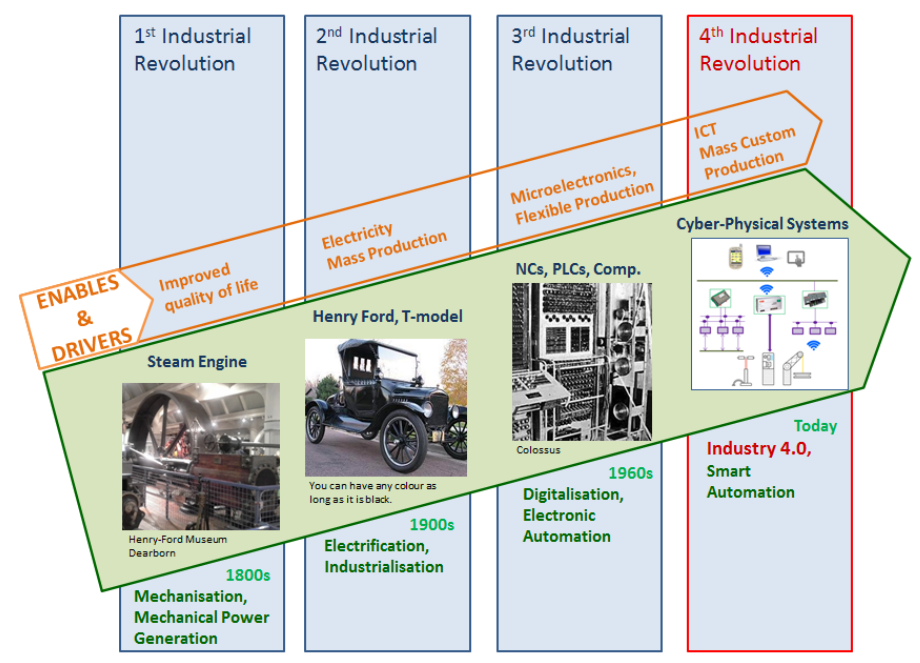

Fig. 1. Through the industrial revolutions 
Today we are in the fourth industrial revolution that was triggered by the development of Information and Communications Technologies (ICT). Its technological basis is smart automation of cyber-physical systems with decentralized control and advanced connectivity (IoT functionalities). The consequence of this new technology for industrial production systems is reorganization of classical hierarchical automation systems to self-organizing cyber physical production system that allows flexible mass custom production and flexibility in production quantity.

\subsection{Origin of Industry 4.0 concept}

That the Industry 4.0 concept comes from Germany is not surprising, since Germany has one of the most competitive manufacturing industries in the world and is even a global leader in the sector of manufacturing equipment. Industry 4.0 is a strategic initiative of the German government that traditionally heavily supports development of the industrial sector. In this sense, Industry 4.0 can be seen also as an action towards sustaining Germany's position as one of the most influential countries in machinery and automotive manufacturing.

The basic concept was first presented at the Hannover fair in the year 2011. Since its introduction, Industry 4.0 is in Germany a common discussion topic in research, academic and industry communities at many different occasions. The main idea is to exploit the potentials of new technologies and concepts such as:

- availability and use of the internet and IoT,

- integration of technical processes and business processes in the companies,

- digital mapping and virtualization of the real world,

- 'Smart' factory including 'smart' means of industrial production and 'smart' products.

Besides being the natural consequence of digitalization and new technologies, the introduction of Industry 4.0 is also connected with the fact that many up to now exploited possibilities for increasing the profit in the industrial manufacturing are almost exhausted and new possibilities have to be found. Namely the production costs were lowered with introduction of just-in-time production, by adopting the concepts of lean production and especially by outsourcing production to countries with lower work costs. When it comes to the decreasing costs of industrial production, Industry 4.0 is a promising solution. According to some sources, Industry 4.0 factory could result in decrease of [4]:

- production costs by $10-30 \%$,

- logistic costs by $10-30 \%$,

- quality management costs by $10-20 \%$.

There are also a number of other advantages and reasons for the adoption of this concept including: (1) a shorter time-to-market for the new products, (2) an improved customer responsiveness, (3) enabling a custom mass production without significantly 
increasing overall production costs, (4) more flexible and friendlier working environment, and (5) more efficient use of natural resources and energy.

\subsection{Industry 4.0 production system (Smart factory)}

Figure 2 depicts the Industry 4.0 smart factory. The core process is digital to physical conversion in a reconfigurable manufacturing system. Reconfigurable manufacturing systems are the latest advance in the development of a manufacturing system. First step were fixed production lines with the machines dedicated to the performance of specific tasks so only one product could be produced. Next step were flexible production systems with programmable machines that allowed production of a variety of different products but offered no flexibility in the production capacity [5]. As the results of the latest development are reconfigurable manufacturing systems able to adapt their hardware and software components to follow ever-changing market requirements of type and quantity of the products [6], [7].

Machines in Industry 4.0 factory are Cyber-Physical Systems, physical systems integrated with ICT components. They are autonomous systems that can make their own decisions based on machine learning algorithms and real-time data capture, analytics results, and recorded successful past behaviours. Typically, programmable machines (CNC and NC) are used, with a large share of mobile agents and robots able of self-organization and self-optimization.

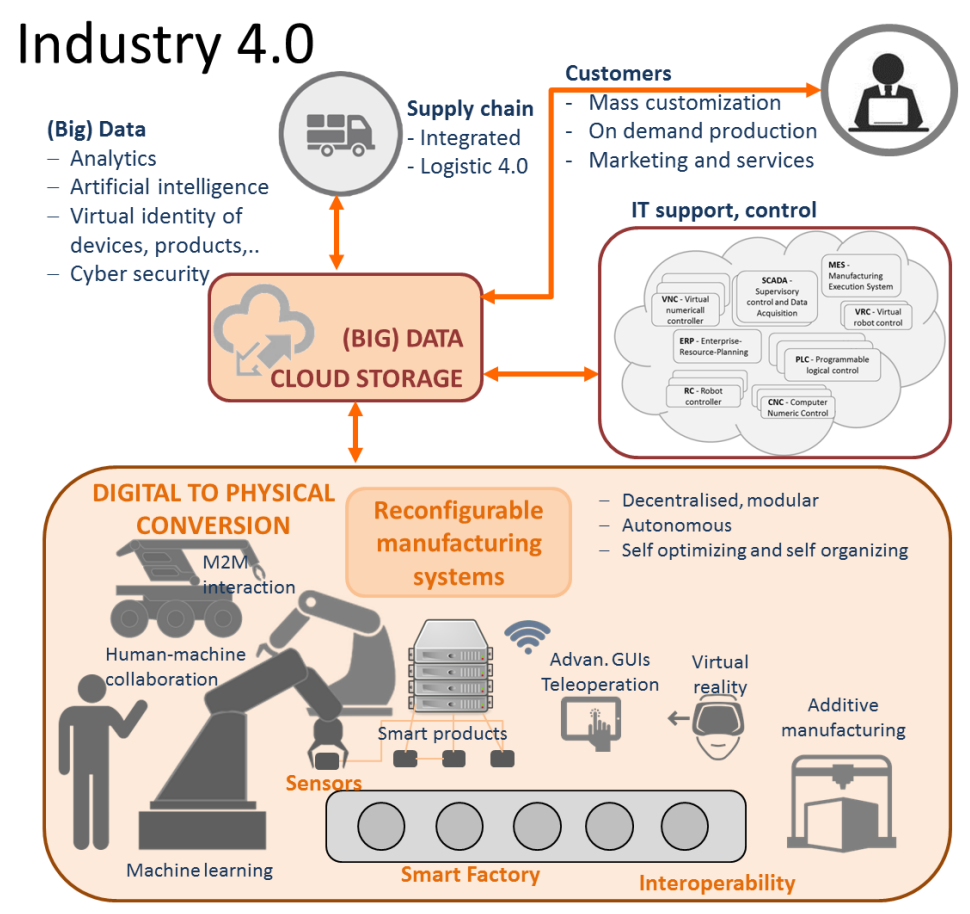

Fig. 2. Industry 4.0 smart factory 
Products in such factory are also 'smart', with embedded sensorics that is used via wireless network for real-time data collection for localization, for measuring product state and environment conditions. Smart products also have control and processing capabilities. Thus they can control their logistical path through the production and even control/optimize the production workflow that concerns them. Furthermore, smart products are capable of monitoring their own state during the whole life cycle, including during their lifetime/application. This enables proactive, condition-based maintenance that is especially valuable for products embedded in larger systems (like for example power converters in electric grids) [8].

In Industry 4.0, the production elements have beside their physical representation also virtual identity, a data object that is stored in the data cloud. Such virtual identity can include a variety of data and information about the product, from documents, to 3$\mathrm{D}$ models, individual identifiers, current status data, history information and measurement/test data.

Important elements of the Industry 4.0 concept are also interoperability and connectivity. A continuous flow of information between the devices and components, Machine-To-Machine interaction (M2M), manufacturing systems and actors should be established. Hereby the machines, products and factories can connect and communicate via the Industrial IoT (mostly based on wireless network). Another important topic is Human-To-Machine (H2M) collaboration that is necessary as some production tasks are too unstructured to be fully automatized. A lot of research effort is currently also invested in so called collaborative robotics. Here human workers and especially designed compliant robots work together in the execution of complex and unstructured work tasks at the manufacturing production line. Such tasks were done completely manually before. Advanced user interfaces are developed for new forms of $\mathrm{M} 2 \mathrm{H}$ communication. They often include teleoperation and are based on augmented reality environments.

Between the Industry 4.0 manufacturing technologies, additive manufacturing, such as $3 \mathrm{D}$ printing, is often mentioned as one of the key technologies. In combination with rapid prototyping methods including 3D modelling, a direct digital thread can be established from design to production, facilitating a shorter time from the idea to the product. Until now, however, additive manufacturing processes cannot always reach the same quality as a conventional industrial process and some new materials still need to be developed.

\section{$2.4 \quad$ IT support}

Software tools are crucial for operating of the Industry 4.0 smart factory. Figure 3 depicts the well known pyramid structure of support software of modern production systems.

On the business level, the Enterprise Resource Planning (ERP) tool is implemented. ERP supports enterprise-wide planning such as business planning, supply chain management, sales and distribution, accounting, human resource management and similar. Usually commercially available solutions are implemented. Currently the leading solution is SAP, by the German company SAP SE [9]. In traditional ERP 
tools, the decision process is centralized on the highest level in the automation pyramid. Most of the available ERP solutions do not support fast adaptation in production planning due to the unplanned events.

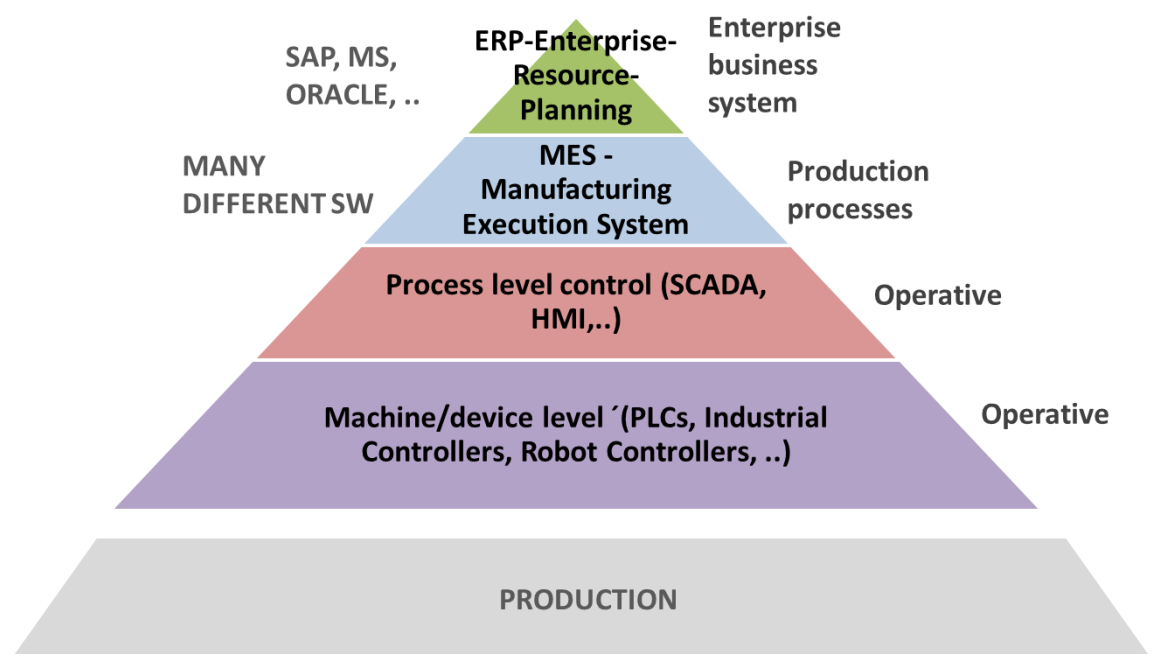

Fig. 3. Automation pyramid in modern production systems

The second level in the traditional automation pyramid is Manufacturing Execution System (MES). It supports production reporting, scheduling, dispatching, product tracking, maintenance operations, performance analysis, workforce tracking, resource allocation and similar. It covers aspects such as management of the shop floor and communication with the enterprise (business) systems. Most of the software solutions available on the market are centralized and not distributed to the shop floor elements. This is a major limiting factor when flexibility is needed due to the dynamics of customers' order flow and/or changing production environment, including shop floor configuration.

The next operative level is process level control based on Supervisory Control and Data Acquisition (SCADA) control system architecture followed by controllers on machine/device level such as Programmable Logic Controllers (PLCs), robot controllers and other controllers.

The last level of the automation pyramid is a machine/device level. In opposition to the top two layers, this level has a naturally distributed control level.

ERP and MES tools represent basic software in the company and are used since the nineties. Both systems have typically a modular structure but are centralized in their operation and thus have limited capability for dynamic adaptation of the production plan [10]. Nevertheless, already implemented conventional ERP and MES systems should not be seen as main obstacles to the introduction of the Industry 4.0 concept but more as a step towards it. Namely already the introduction of a common MES tool requires advanced IT infrastructure on the shop floor level and this is also a precondition for further development towards smart factory. 
The next important issue is information integration among ERP, MES and other software tools used in the company such as, for example, Customer-RelationshipManagement (for help at managing relationships with the outside) and Business Intelligence (for business analysis purposes). The problems such as database integration and communication protocols need to be resolved [10].

It can be concluded that for the Industry 4.0 the classical automation structure does not present the best solution as it is not flexible enough for adapting to the dynamic changes in the order flow and at the shop floor. Distributed MES solution, where most of the functions are decentralized, is expected to be more suitable for the reconfigurable production systems, Figure 4. For full support of reconfigurable systems, a continuous flow of information (vertical and horizontal integration) between all elements should be realized.

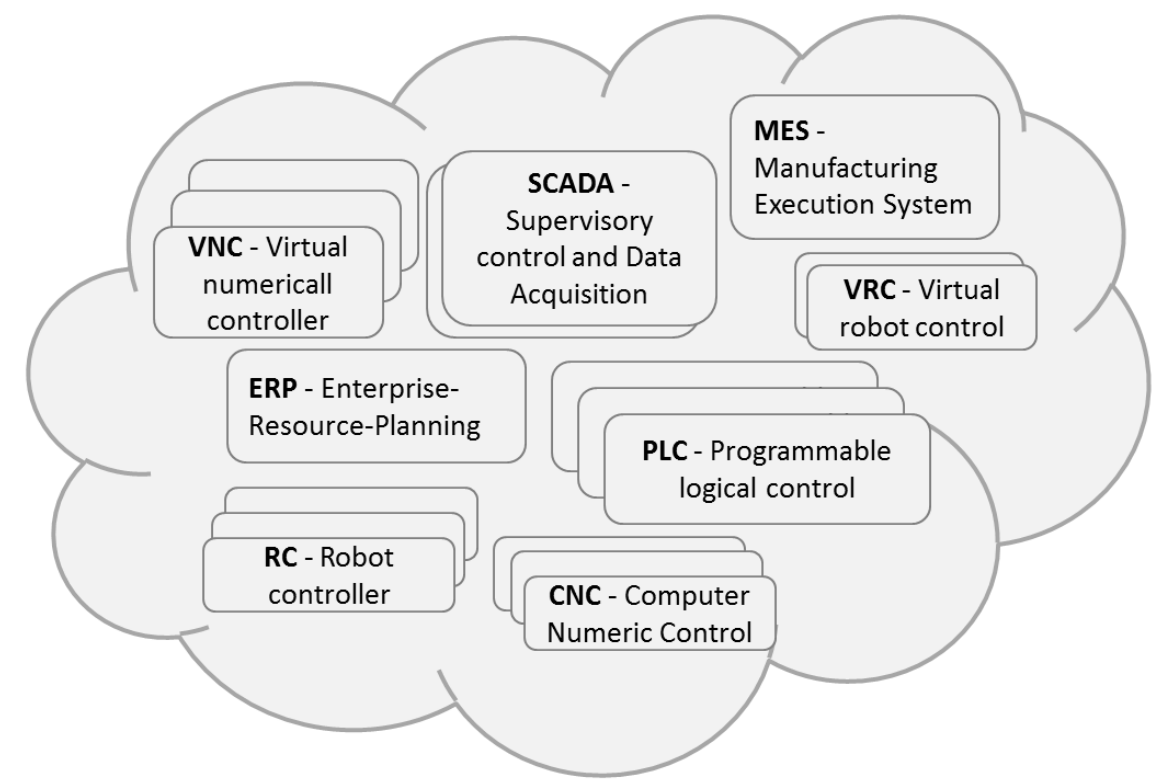

Fig. 4. Industry 4.0 structure of IT support and operative level control in the industry

\section{$3 \quad$ Reference architecture model RAMI4.0}

It is clear that the Industry 4.0 concept will be in most companies realized by using already available equipment and technologies. Only when a new production system is planned, there is an opportunity to design the production system already from the beginning as Industry 4.0 system. Therefore one of the challenges is how already available standards will be integrated into the new concept.

To address the standardization issue, a Reference Architecture Model for the Industry 4.0 (RAMI4.0), Figure 5, was developed in Germany [11]. 


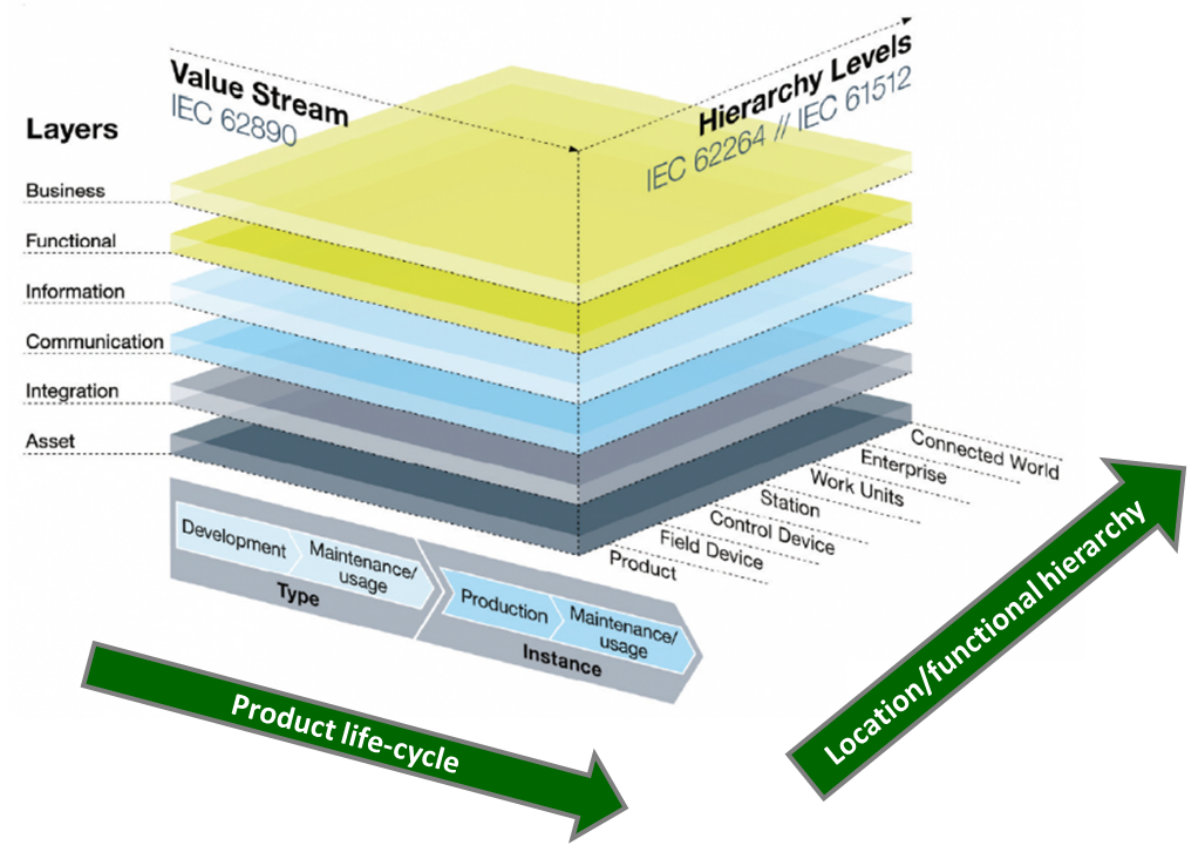

Fig. 5. Reference Architecture Model for Industry 4.0 [11]

This is a meta-model so it describes the aspects that play an important role in the Industry 4.0 production system. It is based on the internationally accepted Smart Grids architecture model introduced in year 2014, however with two additional bottom layers to address specific aspects of Industry 4.0. The three dimensional RAMI4.0 should enable:

- identification of the existing standards,

- identification and closure of gaps and loopholes in the existing standards,

- identification of overlaps in the existing standards.

The first dimension of the RAMI4.0 addresses two elements, type and instance. As long as an idea, a concept, or a product is still a plan and is not available/realized yet, it is called type. The second dimension of the model deals with location, functional hierarchy from the product to the connected world (as the last stage of Industry 4.0 development with all enterprises, customers and suppliers connected). The third dimension of the RAMI4.0 model is organized in functional layers as follows [11]:

- An assets layer includes physical components such as robots, conveyer belts, PLCs, documents, archives, but also non-physical objects such as software and ideas.

- An integration layer provides information for assets in a form that can be digitally processed. It includes elements connected to IT such as sensors, integration to HMI and computer-aided control of technical processes. 
- A function of the communication layer is standardization of communication using uniform data format and predefined protocols. It also provides services for the integration layer.

- An information layer is processing and integrating available data into useful information.

- A functional layer includes formal descriptions of functions. Also ERP functions belong to this layer.

- A business layer includes mapping of the business model and links between different business processes.

RAMI4.0 is in Germany registered as DIN SPEC 91345 and it is as such a first compilation of the essential technological elements of Industry 4.0. It is perceived as a precondition for deployment of Industry 4.0 concept in practice and also as a model that requires international acceptance.

\section{$4 \quad$ Current state of Industry 4.0}

When considering the current state of the Industry 4.0, it is important to understand the preconditions that have to be fulfilled so that a new concept can be introduced in industrial manufacturing system. At least the following has to be fulfilled:

- Stability of the production has to be guaranteed also during the transition phase.

- Stepwise investment should be possible as most of the industrial processes cannot bear big one-time investments.

- A good know-how protection is necessary. Closely connected is the cybersecurity issue.

Furthermore the industry concept is not limited just to the production system but it includes the complete value chain (from suppliers to the customers of one enterprise towards the 'Connected Word' of all enterprises) and all enterprise's functions and services. It is clear that it is not easy to fulfil these criteria, therefore only some 'islands' of the Industry 4.0 concept currently exist.

To evaluate the current state the German organization 'Verband Deutscher Maschinen- und Anlagenbau' has conducted a study on the readiness of Germany companies for Industry 4.0. The following six dimensions were evaluated, [12]:

- Strategy and organization (investments, innovations management),

- Smart factory (equipment and IT systems, data capturing and usage, digital modelling),

- Smart operation (integration of value chain, cloud storage),

- Smart products (physical components, virtual identity),

- Data-driven services (ICT functionalities, prediction and optimization of business outcomes, ..),

- Human resources (employees skills, continuous education). 
A survey was conducted of 268 companies from Germany with more than $20 \mathrm{em}-$ ployees, [12]. The results showed that $56.5 \%$ of all participating companies are not fulfilling any requirements concerning Industry 4.0 readiness. Further, $20.1 \%$ of the companies are assessed to be on the Level 1 (beginner), which means that the company is involved in Industry 4.0 through pilot initiatives in various departments and investments. This is however limited to a single area and only few processes are already supported by IT systems. Only $0.3 \%$ of companies ( 8 companies from 268 that were participating) are ranked on the Level 5 (top performer). This means that they have already implemented the Industry 4.0 strategy and have sufficiently addressed all six evaluated dimensions.

One of the few companies that has already implemented the Industry 4.0 concept is the German company SEW Eurodrive from Baden-Württemberg [13]. The basis of their approach is manufacturing logistic based on so called 'mobile assistants'. The mobile assistants are autonomous mobile platforms that move through the shop-floor carrying material, half-products and tools. In the attached Radio-Frequency Identification (RDIF) chips mobile assistants also carry all information concerning the required manufacturing processes. When a new customer order arrives the mobile assistant collects the necessary material and autonomously brings it from workstation to workstation, according to the order of necessary manufacturing processes. At the workstations that are cyber-physical systems, the mobile assistant connects to the machine and provides necessary information. At the workstations based on manual human work, the communication with the worker is established via user interface running on a tablet.

As a result, the productivity of the SEW company has been increased and the workers were relieved from most of the heavy manual labour connected with transporting and displacing of material and half-products. According to [14], the only limitation towards complete automation in this company is a human factor. For example, when constituting working teams for a specific product it needs to be considered who can most efficiently work together. Such decisions can of course not be automated.

\section{Conclusions and Discussion}

In this paper, the background and development of the Industry 4.0 concept are presented. Although the concept is very comprehensive and complex, three main points can be identified:

- The Industry 4.0 concept is not limited just to the direct manufacturing in the company but it includes also a complete value chain from providers to customers and all enterprise's business functions and services.

- The Industry 4.0 assumes broad support of an entire life cycle of systems, products and series, distributed both spatially and organizationally. The smart products are not smart only during the manufacturing process but they continue to provide the data about their state also during their lifetime. These data can be used for preventive maintenance; it can provide the manufacturer useful information about lifetime and reliability of their products. 
- The Industry 4.0 is a specialization of the Internet of Things applied to the manufacturing/industrial environment. It assumes a real-time data collection leading to the issue of handling and analysing huge data and cybersecurity.

Finally, let us consider a generally accepted opinion about the role and future of the Industry 4.0 concept. Namely the Industry 4.0 is often considered as disruptive technology that will pave the way to a new generation of industrial manufacturing systems that will be completely different than the existing ones. Further, the Industry 4.0 is generally adopted as a concept of the fourth industrial revolution. This opinion does however require a closer look since the fourth industrial revolution is the first industrial revolution that was announced in advance and not when it was already fully developed.

On the other hand, Industry 4.0 can be also perceived as a natural transformation of the industrial production systems triggered by the digitalization trend. This hypothesis is supported by comparison of 'conventional' topics in industrial production systems and Industry 4.0 topics depicted in Figure 6. It is obvious that the main issues/topics did not really change, just the technology and approaches for tackling the connected issues are new.

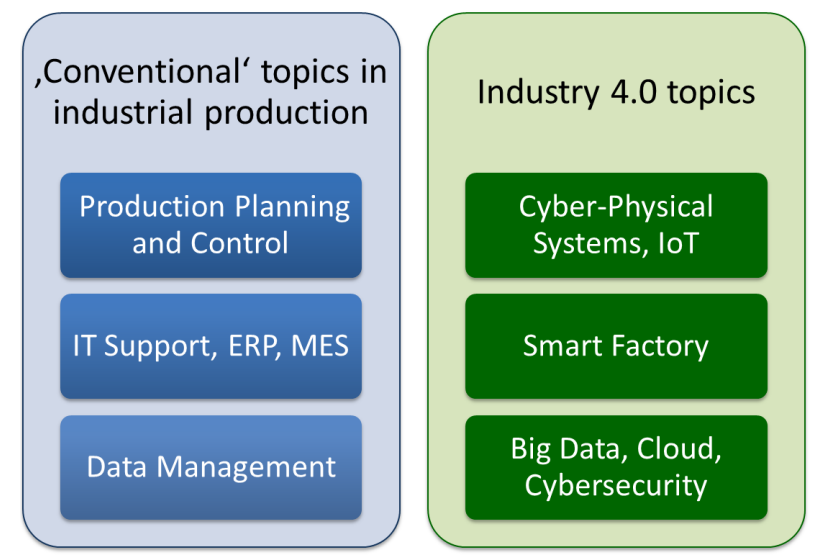

Fig. 6. Comparison of topics in conventional industrial production and the Industry 4.0 topics

Five years after the introduction in Germany, the Industry 4.0 concept is known worldwide and it has been also transferred from its original application field in industrial manufacturing to other engineering and non-engineering fields. The corresponding concepts such as Automotive 4.0, Logistic 4.0 and Education 4.0 have in common with original meaning of Industry 4.0 only extensive usage of ICT tools, connectivity and capture and analysis of real-time data.

The way towards wider deployment of the Industry 4.0 production concept is still long. There are only very few Industry 4.0 enterprises, mostly new enterprises built to prove the concept. It can be expected that most of the enterprises will introduce the Industry 4.0 elements gradually and by building on already existing equipment and software solutions, thus not endangering the stability of their production. 


\section{References}

[1] Industrial Internet Consortium, Industrial Internet Reference Architecture,Version 1.7, 2015.

[2] Presentation at the French Embassy in the Germany, "Industry of the future", 2015. Available at. http://www.ambafrance-de.org/Vorstellung-des-neuen-franzosischen-PlansIndustrie-du-Futur-in-der-Botschaft. Last accessed: 24.11.2016.

[3] The State Council of the People's Republic of China, "Made in China 2025", Available at: http://english.gov.cn/2016special/madeinchina2025/. Last accessed: 24.11.2016.

[4] Thomas Bauernhansl, Jörg Krüger, Gunther Reinhart, Günther Schuh: Wgp-Standpunkt Industrie 4.0, Wissenschaftliche Gesellschaft für Produktionstechnik Wgp e. v., 2016.

[5] U.R. Dhar, "Flexible manufacturing systems: Major breakthrough in manufacturing management“, Elsevier Engineering Management International, Volume 5, Issue 4, May 1989, Pages 271-277.

[6] Yoram Korena, Moshe Shpitalnib, "Design of reconfigurable manufacturing systems", Elsevier Journal of Manufacturing Systems, Volume 29, Issue 4, October 2010, Pages 130-141. https://doi.org/10.1016/j.jmsy.2011.01.001

[7] N. G. Nayak, F. Dürr and K. Rothermel, "Software-defined environment for reconfigurable manufacturing systems, "Internet of Things (IOT), 2015 5th International Conference on the, Seoul, 2015, pp. 122-129.

[8] B. C. Morello, B. Ghaouar, C. Varnier and N. Zerhouni, "Memory tracking of the health state of smart products in their lifecycle," Industrial Engineering and Systems Management (IESM), Proceedings of 2013 International Conference on, Rabat, 2013.

[9] SAP SE, Available at: http://go.sap.com/corporate/en.html. Last accessed: 24.11.2016.

[10] A. Bratukhin, T. Sauter, "Functional Analysis of Manufacturing Execution System Distribution," IEEE Transactions on Industrial Informatics, Vol. 7, No. 4, Nov. 2011, pp. 740749. https://doi.org/10.1109/TII.2011.2167155

[11] Referenzarhitekturmodell Industrie 4.0 (RAMI4.0), VDI/VDE Gesellschaft Mess- und automatizierungstechnik, April 2015.

[12] Verband Deutscher Maschinen- und Anlagenbau. Industrie 4.0 readiness, Cologne Institute for Economic Research (IW) and Aachen University 2015.

[13] SEW EURODRIVE: 'Industrie 4.0 - Unsere Vision der Lean Sm@rt Factory'. Available at: https://www.sew-eurodrive.de/unternehmen/ihr erfolg/zukunftsthemen/industrie 40/ industrie 40.html. Last accessed: 30.11.2016.

[14] SEW EURODRIVE: 'Industrie 4.0' (German). Available at: http://video2.spiegel.de/flash/12/41/1701421 1024x576 H264 HQ.mp4. Last accessed: 30.11.2016.

[15] IMPULS Foundation of the German Engineering Federation (VDMA), Industrie 4.0 readiness check tool for companies, Available at: https://www.industrie40readiness.de/?lang=en. Last accessed: 24.11.2016.

[16] K. Zhou, Taigang Liu and Lifeng Zhou, "Industry 4.0: Towards future industrial opportunities and challenges“, Conference on Fuzzy Systems and Knowledge Discovery, 2015, pp. 2147-2152. 


\section{$7 \quad$ Author}

Andreja Rojko received a $\mathrm{PhD}$ degree in Electrical Engineering from the University of Maribor, Slovenia in 2002. Afterwards she was with Institute for Robotics at the University of Maribor. In February 2016 she joined ECPE - European Center for Power Electronics, Nuremberg, Germany. (e-mail: andreja.rojko@ecpe.org).

Article submitted 27 April 2017. Published as resubmitted by the author 10 June 2017. 